\title{
Transient global amnesia and Takotsubo syndrome: would cerebral blood flow brain scan be of any help?
}

\author{
John E. Madias ${ }^{1,2}$
}

Received: 1 April 2015/Accepted: 20 April 2015/Published online: 10 May 2015

(C) Springer-Verlag Berlin Heidelberg 2015

To the Editor,

The article by Quick et al. [1], published online ahead of print on March 31, 2015 in the Journal, about the 57-yearold woman who suffered transient global amnesia (TGA) in the setting of Takotsubo syndrome (TTS), is of great interest because it hints at the possible pathophysiologic underpinnings of TTS [2]. The authors succinctly summarize what is currently known about the pathophysiology of TGA and TTS, both of which continue to be elusive. They refer to the laboratory studies of cranial computed tomography and electroencephalography that the patient underwent, both of which revealed no abnormalities. The authors also state that "although the etiology of TGA remains controversial, there is consensus that the areas involved are the hippocampus and the parahippocampus region" [1]. This brought to mind a recent report by Suzuki et al. [3-5], who assessed cerebral blood flow (CBF) in three consecutive patients with TTS, using (99 m) Tc-ethyl cysteinate dimmer single photon-emission computed tomography, on admission and at follow-up, after the myocardial function had recovered, and found that CBF, as a reflection of the underlying brain activity, is enhanced in the hippocampus, brainstem, and basal ganglia in the acute phase of TTS, and decreased in the prefrontal cortex, with partial normalization of these changes at follow-up. The authors did not perform a 3rd scan to evaluate whether these CBF abnormalities were completely reversed in their patients with TTS [4, 5], or if the abnormalities constitute the baseline for patients probably prone to develop TTS. One wonders whether brain scanning for CBF may be of help in elucidating the pathogenetic basis of TGA.

Conflict of interest On behalf of all authors, the corresponding author states that there is no conflict of interest.

\section{References}

1. Quick S, Speiser U, Richter N, Youssef A, Waessnig N, Strasser RH, Ibrahim K (2015) Transient global amnesia and broken heart syndrome: two faces of one pathology. Clin Auton Res (Epub ahead of print)

2. Samuels MA (2007) The brain-heart connection. Circulation 116:77-84

3. Suzuki H, Matsumoto Y, Kaneta T, Sugimura K, Takahashi J, Fukumoto Y, Takahashi S, Shimokawa H (2014) Evidence for brain activation in patients with takotsubo cardiomyopathy. Circ $\mathrm{J}$ $78: 256-258$

4. Madias JE (2014) Cerebral blood flow in takotsubo syndrome: is it specific for the disease? Circ J 78:775

5. Suzuki H, Matsumoto Y, Shimokawa H (2014) Cerebral blood flow in takotsubo syndrome: is it specific for the disease? Circ J $78: 776$

John E. Madias

madiasj@nychhc.org

1 Icahn School of Medicine at Mount Sinai, New York, NY, USA

2 Division of Cardiology, Elmhurst Hospital Center, 79-01 Broadway, Elmhurst, NY 11373, USA 